\title{
As influências conceituais do cristianismo sobre a deficiência: o papel do Ensino Religioso na construção de sujeitos de direitos'
}

Thyeles Moratti Precilio Borcarte Strelhow*

\section{Resumo}

A tradição cristã, desde seus inícios, esteve envolvida com as pessoas com deficiência propondo alternativas às condições encontradas na realidade social histórica por meio de suas práticas diaconais. Essas açôes contribuíram para romper com a ideia de castigo divino. Porém, foram-se conceituando ideias vinculadas com a religiosidade cristã como: "presente de Deus, Deus quis assim ou Deus não dá uma cruz maior que não se possa carregar". Com a ascensão de uma era pautada pelos direitos humanos e pela luta das pessoas com deficiência por ocupação do espaço social e participação cidadâ, estas visões acabaram por se tornar símbolos da estigmatização da deficiência. Desta forma, a partir de pesquisa bibliográfica, este artigo pretende apontar alguns aspectos que o Ensino Religioso, em sua prática pedagógica, pode contribuir para reinterpretar as imagens da deficiência a partir de uma perspectiva inclusiva. Conclui-se que conceitos como reconhecimento, conhecimento e inclusão precisam ser entendidos a partir de uma perspectiva de alteridade, corroborando para a construção da pessoa com deficiência como sujeito de direitos.

Palavras-chave: Deficiência; Ensino Religioso; Sujeitos de direitos. 


\section{The conceptual influences of Christianity on disability: the role of Religious Education in the construction of subjects of rights}

\section{Abstract}

The Christian tradition, from its beginnings, was involved with people with disabilities proposing alternatives to the conditions found in historical social reality through their diaconal practices. These actions contributed to break with the idea of divine punishment. However, ideas related to Christian religiosity were conceptualized as: " gift of God, God wanted it or God does not give a bigger cross that can not be carried". With the rise of a human rights era and the struggle of people with disabilities for occupying the social space and citizen participation, these visions eventually became symbols of the stigmatization of disability. In this way, from a bibliographical research, this article intends to point out some aspects that the Religious Teaching, in its pedagogical practice, can contribute to reinterpret the images of the deficiency from an inclusive perspective. It is concluded that concepts such as recognition, knowledge and inclusion need to be understood from a perspective of otherness, corroborating for the construction of the disabled person as subject of rights.

Keywors: Disability; Religious Education; Subjects of rights.

\section{Introdução}

Ao falar sobre as concepçôes cristãs a respeito da deficiência, inevitavelmente se volta os olhares para a história antiga rebuscando de alguma forma para alguns fatos e elementos que remontem a um início ou começo. Neste artigo náo é diferente, atenta-se para história para, de alguma forma, compreender alguns desenvolvimentos atuais que especificamente traçam um perfil de compreensão do imaginário comum sobre a pessoa com deficiência. Há que deixar claro que todo e qualquer entendimento histórico precisa ser compreendido dentro de seu acontecimento dentro da história. A História não é linear e não acontece num vácuo ou num nada. Pelo contrário, ela é concreta e se relaciona com as vidas cotidianas das pessoas. Desta forma, compreender as imagens cristâs construídas sobre a deficiência no percurso histórico compreende um processo a ser lido dentro de seu momento, considerando suas peculiaridades, sem uma transposição automática do hoje para o ontem.

O fato de olhar para o desenvolvimento histórico das constituiçóes das imagens sobre as pessoas com deficiência deve ser entendido como um processo refratário da realidade. É impossível que se chegue à realidade histórica em sua totalidade, no entanto, é fundamental que se faça este exercício para poder entender alguns processos importantes. Nesse sentido, essa tarefa compreende reconhecer a necessidade e sua contribuição de determinados processos históricos para a construção sobre a deficiência e o manejo com estas pessoas. Assim, a relaçáo de cuidado elaborada pelo início da cristandade para as pessoas com deficiência da época constituiu-se num aspecto fundamental para o seu reconhecimento, mas, em outro processo, as ideias mágicas sobre a deficiência tornaram-na fruto da ira divina. 
Estas concepçôes, de certa maneira, entram em confronto com a perspectiva da educação inclusiva, apoiada no ideal dos direitos humanos, de que todas as pessoas são capazes de aprender, mas de formas diferentes. Isto porque, seja pela caracterização de dependência caritativa ou pela designação de incapacidade, ambas não qualificam a pessoa com deficiência como protagonista do seu processo de aprendizagem. Assim, este artigo tem a pretensão de apontar alguns aspectos que o Ensino Religioso, em sua prática pedagógica, pode contribuir para reinterpretar essas imagens da deficiência, a partir de uma perspectiva inclusiva, trazendo para o centro a pessoa com deficiência e sua potencialidade de exercer um papel de sujeito.

\section{Metodologia}

Para tratar sobre a metodologia utilizada na realizaçáo desta pesquisa bibliográfica em caráter exploratório, almejando aproximar-se do tema, é importante destacar que os resultados parciais aqui apresentados fazem parte do projeto de pesquisa que visa compreender como as pessoas com deficiência percebem sua inclusão no mundo do trabalho e em que medida as concepçóes sobre a deficiência interferem na ocupção do espaço social do trabalho. Desta forma, foi levantada e catalogada bibliografia diversa (textos, teses, dissertaçóes, livros, artigos) que tratasse sobre a temática das concepçôes sobre a deficiência. Neste aspecto, em relação à construção deste artigo, os resultados e a discussão aqui apresentada têm como base as compreensóes cristâs sobre a deficiência construídas historicamente, com uma atualizaçấo interligada com a prática do Ensino Religioso e os direitos humanos.

\section{As imagens da deficiência na tradição cristã}

Ao se tratar sobre as imagens da deficiência na tradição cristã pretende-se, num movimento difícil, mas necessário, indicar conceituaçôes que caracterizavam as pessoas com deficiência em determinadas épocas através de suas relaçôes de atendimento. Acredita-se que, de certa forma, algumas destas concepçóes influenciaram as identificaçôes das pessoas com deficiência na atualidade. Isto porque, não é incomum encontrar alocuçôes discursivas junto ao senso comum que qualifiquem as pessoas com deficiência como "presente de Deus, anjo/a, iluminado/a, vontade de Deus" etc. Bianchetti destaca que

a mitologia assim como as grandes religióes e especialmente a literatura [...] são fontes imprescindíveis para compreender o ser-pensar-agir-sentir dos homens e mulheres nos dias atuais. Isto mostra a operacionalidade que há nos relatos mitológicos ou na história original das religióes, o que deveria desafiar-nos a estudá-las e buscar compreendê-las mais por aquilo que nos revelam da nossa filoontogênese - se assim pudéssemos falar, ao fazer referência a esse amálgama que forja o pensamento ocidental judaico-cristáo -, do mais profundo e longínquo de cada um de nós e da própria humanidade, do que por simples curiosidade ou diletantismo. (BIANCHETTI, 2001, p. 65).

Estas formulaçóes são utilizadas, em muitos casos, como uma forma de resolver as frustraçóes pela espera do/a filho/a idealizado/a ou pelo confronto com o diferente. (BUSCAGLIA, 1993, p. 105.). Desta forma, entender a deficiência assim 
torna-se um jeito tolerante de conviver com a pessoa com deficiência através de uma concepçáo de caridade, que em certo ponto remonta às primeiras comunidades cristâs e seu cuidado para com as pessoas marginalizadas.

São interessantes as observaçóes que Pessotti traz em seu livro a propósito do desenvolvimento do entendimento sobre a deficiência mental ao longo da história. Ele salienta que com o florescer do cristianismo (SILVA, 1987. p. 153) ${ }^{2}$ e de sua doutrina, a pessoa com deficiência passa de uma coisa para uma pessoa, no entanto, esta igualdade ainda náo é reconhecida como uma igualdade civil. Nas palavras de Pessotti:

\begin{abstract}
Graças à doutrina cristã os deficientes começam a escapar do abandono ou da "exposição", uma vez que, donos de uma alma, tornam-se pessoas e filhos de Deus, como os demais seres humanos. É assim que passam a ser, ao longo da Idade Média, "les enfants du bon Dieu", numa expressão que tanto implica a tolerância e a aceitaçáo caritativa quanto encobre a omissão e o desencanto de quem delega à divindade a responsabilidade de prover e manter suas criaturas deficitárias. Como para a mulher e o escravo, o cristianismo modifica o status do deficiente que, desde os primeiros séculos da propagaçáo do cristianismo na Europa, passa de coisa a pessoa. Mas a igualdade de status moral ou teológico não corresponderá, até a época do iluminismo, a uma igualdade civil, de direitos. Dotado de alma e beneficiado pela redençáo de Cristo, o deficiente mental passa a ser acolhido caritativamente em conventos ou igrejas, onde ganha a sobrevivência, possivelmente em troca de pequenos serviços à instituiçáo ou à pessoa "benemérita" que o abriga. (PESSOTTI, 1984. p. 04-05).
\end{abstract}

Desta citação quer se chamar a atenção para duas questôes consideradas fundamentais e que, de forma direta ou indireta, influencia os pensamentos modernos sobre as pessoas com deficiência em nível social e em nível de política pública. $\mathrm{O}$ primeiro ponto que se quer salientar é a expressão "os filhos do bom Deus" (tradução livre). Essa expressão é significativa, pois remonta à ideia corrente de que a pessoa com deficiência é autoafirmada como criatura divina e por isso ela deve ser cuidada e mantida com uma vida digna. De fato, pela perspectiva cristã, reconhecer que a pessoa é filha de Deus é torná-la parte da comunidade, uma forma de justificar os cuidados e investimentos com seu cuidado. A princípio estas denominaçôes não são um problema em si, no entanto, esta caracterização da pessoa com deficiência contribui para elaboraçóes que retratam a deficiência como santidade (anjo, presente de Deus etc), numa tentativa de normalizar a deficiência aos padróes estigmatizantes de uma faixa da sociedade. A questão que se quer levantar é que até que ponto estas formas de definir a pessoa com deficiência contribuem para que ela sistematicamente seja caracterizada como incapaz e ser sempre qualificada como dependente da boa vontade das pessoas à sua volta. É a este ponto que se quer chegar. Parece que quando se coloca esse estigma sobre a pessoa com deficiência, as barreiras sociais crescem imensamente tornando-se praticamente intransponíveis, sendo um entrave para que práticas inclusivas aconteçam. Isto porque as concepçóes que se fomentam a respeito da outra pessoa definem, em parte, os investimentos que se fará em relação a esta. (GONZÁLEZ, 2005, p. 167-181)3. Logo, se a pessoa com deficiência é vista como incapaz esta será tratada como tal. 
Uma segunda questão que se quer levantar é em relação ao atendimento das pessoas com deficiência. Espera-se que as concepções de atendimento estejam embasadas na relação dos direitos humanos, porém, porventura, se entenda a pessoa com deficiência de maneira infantilizada, gera-se um atendimento por caridade. Quando não se reconhece o papel de protagonismo da pessoa com deficiência, ela deixa de ser sujeito de direitos para ser sujeito de concessão. Quer dizer, ela se torna dependente de uma ação beneficente específica. $\mathrm{O}$ que é direito (acessibilidade à sociedade em geral, por exemplo) passa a ser uma obra de caridade (autorização para acessar a sociedade em geral).

O "x" da questáo está na transmutação de uma ideia de forma a-histórica. Não se pretende demonizar as ações empreendidas no momento histórico em que se encontravam as açôes do excerto acima, porque por mais questionável que seja essa expressão, ela ainda é um avanço em relação à sua época, pois retira a pessoa com deficiência de uma situação de morte, para, ao menos, uma situação de possibilidade de vida. O problema que se quer destacar é quando esse imaginário é transposto para a realidade atual desconsiderando toda a luta por garantia de direitos que as pessoas com deficiência conseguiram ao longo da história por reconhecimento e inclusão. Assim, o atendimento às pessoas com deficiência não é uma bondade da sociedade, mas, pelo contrário, as pessoas com deficiência têm o direito de ocupar os espaços sociais disponíveis para todas as pessoas.

Seguindo esta linha de interpretação a pesquisa realizada por Tupinambá e Reily sobre as retrataçóes das pessoas com deficiência na História da Arte e suas intersecçôes com a origem da Educação Especial reafirmam as constataçóes de Pessotti e fazem um rápido apanhado geral ao longo da história. As autoras descrevem que do surgimento das primeiras comunidades cristãs apresenta-se também uma nova forma de conceber as pessoas com deficiência que contrapóe o modelo espartano e as considera como filhos/as de Deus (TUPINAMBÁ; REILY, 2004, p. 127-136) e esta nova forma também se retrata nas obras de arte da época. Porém, também salientam que no período Medieval as pessoas com deficiência são novamente associadas a uma imagem negativa e depreciativa, como marcas do pecado. No período Renascentista as pessoas com deficiência tomam formas refinadas, com ares de beleza, para transmitir ao público uma ideia de contemplação religiosa. E a partir do Barroco, com um forte apelo no Romantismo, torna-se a olhar para o cotidiano e retratar pessoas com deficiência com o intuito de sensibilizar os/as expectadores/as para o sofrimento do/a outro/a. (TUPINAMBÁ; Reily, 2004, p. 132-134).

O estudo Reily e Tupinambá mostra que as concepçóes teológicas que se desenvolveram na Idade Média quanto à pessoa com deficiência tiveram um caráter, por vezes, dualista e paradoxal. Isto porque, como bem reflete Pessotti, a conduta cristá exige algumas características que váo corroborar para o cuidado da pessoa com deficiência que seria a caridade e a tolerância, virtudes muito valorizadas no pensamento cristão. Pessotti é categórico

Agora a ética cristã reprime a tendência a livrar-se do deficiente através do assassínio ou da 'exposição', como confortavelmente se procedia na Antigüidade: o deficiente tem que ser mantido e 
cuidado. A rejeição se transforma na ambigüidade proteção-segregação ou, em nível teológico, no dilema caridade-castigo. A solução do dilema é curiosa: para uma parte do clero, vale dizer, da organização sociocultural, atenua-se o 'castigo' transformando-o em confinamento, isto é, segregação (com desconforto, algemas e promiscuidade), de modo tal que segregar é exercer a caridade, pois o asilo garante um teto e alimentação. Mas, enquanto o teto protege o cristâo as paredes escondem e isolam o incômodo ou inútil. Para outra parte da sociocultura medieval cristã o castigo é caridade, pois é o meio de salvar a alma do cristão das garras do demônio e livrar a sociedade das condutas indecorosas ou antisociais do deficiente. (PESSOTTI, 1984, p. 07).

Por outro lado, no momento em que a pessoa com deficiência é reconhecida enquanto "filho de Deus", algumas destas características lhes são exigidas e então há um conflito, pois, se esta antes era cuidada como parte da família humana, ela, agora corresponde a uma relação maligna por não corresponder ao ideal cristão de sua época. Assim, muitas pessoas com deficiência na Idade Média, principalmente as com deficiência mental, foram taxadas como possuídas e até merecedoras do castigo divino. Outro ponto importante a ser destacado é a relação que se tem com a pessoa com deficiência que perdurou por muito tempo, e, talvez seja possível dizer, até os dias atuais, com uma tentativa de rompimento com os ideais de inclusão, que é o tratamento segregacionista lhe conferido. Por mais que se constitua num olhar diferenciado para a pessoa com deficiência, considerando-a como "filha de Deus", este cuidado ainda acontecia fora do convívio da sociedade abrangente. Esta ideia de isolamento pode estar relacionada com o mencionado acima que afasta dos olhos dos crentes, as condutas não convencionais do ideário cristão, surtindo assim como uma forma de castigo. Assim fica claro que a relação é de aceitação-rejeição e cuidado-isolamento. (PESSOTTI, 1984, p. 06-07).

\section{O Ensino Religioso e a reinterpretação da deficiência a partir dos direitos humanos: reconhecer para incluir}

O Ensino Religioso (ER) se apresenta como um vasto e fértil campo para discussóes amplas relacionadas às questóes essenciais e existenciais dos sujeitos, a fim de proporcionar momentos de convivência respeitosa, pacífica, tolerante e crítica sobre as diversidades nas quais estâo inseridos. Desta forma, o ER se torna peça fundamental para o exercício consciente de alteridade e de reconhecimento do outro como parte integrante e integral da realidade social. Não há dúvida que esse espaço é fundamental para a formação humana.

Todavia, percebe-se que em algumas práticas o ER é utilizado para proselitismos ou apenas como uma forma de sensibilização a partir de uma crença e em sua maioria cristã. Tanto o é, que na realização da etapa nacional da Conferência Nacional de Educação - CONAE 2014 aprovou-se a troca do nome Ensino Religioso para Ética e Cidadania. Toda a argumentação foi pautada pela forma como o ER é trabalhado nas escolas, contrariando o artigo 33 da LDBEN, bem como, a laicidade do Estado, e tornando-o um espaço de proselitismo. Parece que esta ainda é uma discussão que não se esgotou e precisa ser mais esclarecida para não se perder os avanços já conquistados até o momento em direção a práticas de inclusão e respeito à diversidade religiosa. 
Neste sentido, no tema que se tem abordado neste artigo, o ER pode contribuir de forma efetiva para o reconhecimento das pessoas com deficiência em seu direito à participação, à inclusão e à ocupação dos espaços sociais. Por ser um espaço propício para a reflexão ética sobre temas atuais, que de certa maneira ficam ausentes das discussões de outras disciplinas do ensino, o ER pode proporcionar ressignificaçóes importantes vislumbrando uma sociedade pautada pelo respeito às diversidades e a construção de sujeitos de direitos.

Para esse exercício pretende-se fixar em alguns conceitos que são considerados fundamentais. O primeiro a ser destacado é reconhecimento. Este, em geral, é um conceito chave que está sempre presente quando se trata de diversidades porque, de fato, se não houver o reconhecimento do direito de existência e participação dos atores sociais diversos, não há como conjugar a ação do respeito à diversidade. Reconhecer é entendido aqui, com apoio do Dicionário Eletrônico Houaiss, como "admitir como real, como verdadeiro". Sem dúvida que o exercício de reconhecimento é a conjugação de um processo de admissáo do outro e de sua causa como real, mas num nível muito mais pró-ativo e não apenas passivo. É uma ação em direção ao outro, uma ação de convivência, que busca o contato e não o afastamento "tolerante" cômodo. (LÉVINAS, 1997, p. 197-201). No caso deste artigo é atestar a veracidade de todas as lutas travadas pelas pessoas com deficiência ao longo da história para que hoje, elas possam participar de uma sala de aula regular, que possam ter direito ao trabalho e não destinadas apenas a uma existência de dependência e de caridade. Admitir como real e verdadeiro é estar certo que as pessoas com deficiência têm o mesmo direito de estar onde qualquer um pode estar, e mais, que lhe sejam proporcionadas condiçóes de acessibilidade, nos diversos níveis de ser acessível, para que elas possam participar, principalmente, dos momentos de decisão. Neste sentido, reinterpretar as imagens constituídas sobre a pessoa com deficiência, ligadas à incapacidade, torna-se uma forma consistente de percepção das potencialidades do outro e das limitaçôes próprias de todas as pessoas, construindo assim, uma existência com alteridade. (COSTA; CAETANO, 2014, p. 195-210).

Neste processo de reconhecimento há um termo que não pode ser desconsiderado que é o conhecimento. Tudo que é desconhecido tem um ar de estranheza, e quase como um instinto de sobrevivência, o que se é estranho tem um caráter inicial de ruim e deve ser afastado. Por mais que na atualidade tem-se uma celebração ao novo, este novo que ainda náo é conhecido causa uma sensação de instabilidade que, por sua vez, confronta a limitação de não saber como reagir frente esta realidade que se apresenta. Portanto, compreender um pouco sobre as especificidades e a diversidade que engloba o vasto âmbito das deficiências torna-se uma forma de aproximação que contribui para a ocupação dos espaços sociais pelas pessoas com deficiência.

Outro conceito que é essencial para esta discussão e que, por vezes, é entendido de forma desvirtualizada é a inclusão. Quando o tema da inclusão aparece na discussão, em alguns âmbitos, há uma forte resistência em compreendê-lo. Isto porque os principais argumentos que são elaborados partem de afirmaçôes que desacreditam o processo de inclusão por causa dos modelos já estabelecidos (gastos necessários 
para a inclusão social, educação enquanto excelência de conhecimento técnico etc). Há que salientar que os modelos existentes são excludentes. Nem mesmo as pessoas qualificadas nos padrôes de "normalidade" conseguem estar incluídas completamente. A escola ainda é um espaço de constantes exclusões, seja nos processos avaliativos de aprendizagem, seja nas construçóes modelares de conhecimento, seja no convívio estabelecido pelos papéis de professor/a e a aluno/a, ou, seja nas relaçóes entre ditos iguais (aluno/a x aluno/a; professor/a x professor/a). Novamente se insiste como vem sendo feito ao longo deste artigo, que a inclusão não é um ato de caridade das pessoas classificadas como "normais" para com as pessoas destinadas como "anormais". A normalidade é uma criação que pretende dar uma resolução rápida e imediata para a convivência, pois a relação entre a diversidade é marcada pela tensão. (CARBONARI, 2007, p. 177-179). Este não é um processo fácil, nem muito menos estável. Conviver com a diversidade é um constante reformular-se, apreender-se e desvelar-se de conceitos e construçóes pré-estabelecidas e constituídas como verdade. Assim, o processo de inclusão também é um aceitar-se enquanto incapaz de ser onipotente e um conscientizar-se das próprias limitaçôes. (MANTOAN, 2004, p. 81).

Tomando em conta como base estes três conceitos apresentados resumidamente e brevíssimamente, entende-se que o ER compreende um espaço privilegiado para o rompimento com modelos de educação que exclui e qualifica as pessoas com deficiência como incapazes. Num processo de reconhecimento-conhecimento-inclusão, o ER contribui para a construção de sujeitos integrais que compreendem no convívio com a diversidade a pauta para a construçáo de uma sociedade justa, com igualdade de oportunidades e baseada na efetivação dos direitos humanos.

\section{Conclusões}

Ao fim deste sucinto estudo, muito mais a nível de apresentação de algumas ideias do que suas elaboraçóes profundas pretende-se sistematizar de forma resumida e clara as questóes apresentadas ao longo deste. Vale lembrar que o objetivo desse artigo era apontar alguns aspectos conceituais que o Ensino Religioso, em sua prática pedagógica, pode contribuir para reinterpretar as imagens da deficiência a partir de uma perspectiva inclusiva. Desta forma, passa-se a dois destaques conclusivos.

O primeiro aparte a ser feito diz respeito à impressão de que algumas imagens construídas ao longo da história, principalmente em âmbito cristão, ainda são utilizadas para representar as pessoas com deficiência nos dias atuais. Isto pode ser afirmado a partir de alocuçóes utilizadas para caracterizar as pessoas com deficiência em diferentes âmbitos da sociedade (família, atendimento e senso comum). Estas imagens foram transferidas ao longo da história e perduram para justificar açôes de aceitaçáo e tolerância, uma forma de resolver os desafios que as pessoas com deficiência encontram na sociedade pela ausência de uma efetiva inclusão, ou para justificar a segregação e o afastamento destas pessoas da sociedade envolvente, destinando-as apenas a instituiçôes de atendimento específico. Não se questiona o fato de que as pessoas com deficiência sejam atendidas em suas especificidades, o que se quis problematizar é que estas imagens, em geral, relacionadas à figura da religiấo cristấ, cria uma redoma que incapacita a pessoa com deficiência, tornando-a inapta de atuar na sociedade, em geral, por causa da deficiência. 
O segundo destaque é sobre a importância do ER, em sua prática pedagógica, tornar evidente que muitas das qualificaçóes destinadas às pessoas com deficiência, foram elaboradas há tempos e que sem uma recontextualização tendem a taxá-las por causa de suas deficiências, deixando-se de conceber a pessoa enquanto ser integral, para além de suas limitaçóes. Uma forma que auxilia a romper com os paradigmas da incapacidade é o reconhecimento-conhecimento-inclusão. Esta linha de desenvolvimento pretende a admissáo da pessoa com deficiência como real e verdadeira, o conhecimento de suas lutas e suas especificidades enquanto pessoa e sua inclusão como parte e capaz de participar e ocupar os espaços sociais, principalmente, os de decisão.

\section{Referências}

BIANCHETTI, L. Os trabalhos e os dias dos deuses e dos homens: a mitologia como fonte para refletir sobre normalidade e deficiência. Revista Brasileira de Educaçáo Especial, v. 7, n. 1, p. 61-76, 2001. Disponível em: <http://educa.fcc.org.br/pdf/rbee/v07n01/v07n01a06.pdf>. Acesso em: 12 nov. 2016.

BUSCAGLIA, L. Os deficientes e seus pais. Trad. Raquel Mendes. Rio de Janeiro: Record, 1993.

CARBONARI, P. C. Sujeito de direitos humanos: questôes abertas e em construção. In: SILVEIRA, R. M. G. (et al.). Educaçáo em direitos humanos: fundamentos teórico-metodológicos. Joāo Pessoa: Editora Universitária, p. 169-186, 2007. Disponível em: <http://www.dhnet.org.br/dados/livros/edh/br/fundamentos/12_cap_2_ artigo_04.pdf>. Acesso em: 08 nov. 2016.

COSTA, J. X. S.; CAETANO, R. F. A concepção de alteridade em Lévinas: caminhos para uma formação mais humana no mundo contemporâneo. Revista Eletrônica Igarapé, n 03, p. 195-210, 2014. Disponível em: <http://www.periodicos.unir.br/index.php/igarape/article/viewFile/861/865>. Acesso em: 09 nov. 2016.

GONZÁleZ, F. La Alteridad en la Atención Especial del Autismo. Psicologia Desde El Caribe, n. 15, p. 167-181, 2005. Disponível em: <http://rcientificas.uninorte.edu.co/index.php/psicologia/article/viewFile/1876/1226>. Acesso em: 03 nov. 2016.

LÉVINAS, E. Entre nós: ensaios sobre a alteridade. Petrópolis: Vozes, 1997.

MANTOAN, M. T. E. Caminhos Pedagógicos da Educaçăo Inclusiva. IN: GAIO, R.; MENEGHETTI, R. G. K. (Orgs.). Caminhos Pedagógicos da Educaçáo Especial. Petrópolis: Vozes, p. 79-94, 2004.

PESSOTTI, I. Deficiência mental: da superstição à ciência. São Paulo: T.A.Queiroz/EDUSP, 1984.

SILVA, O. M. A epopeia ignorada: a pessoa deficiente na história do mundo de ontem e de hoje. São Paulo: CEDAS, 1987.

TUPINAMBÁ, A.; REILY, L. H. Retratos de deficiência e doença mental: intersecçôes entre Educaçáo Especial e História da Arte. Revista de Educaçáo PUC-Campinas, Campinas, n. 16, p. 127-136, 2004. Disponível em: <http://periodicos.puc-campinas.edu.br/seer/index.php/reveducacao/article/view/293/276>. Acesso em: 15 nov. 2016.

\section{Notas}

${ }^{1}$ Algumas das ideias aqui apresentadas foram comunicadas em forma de esboço no III Congresso Nacional de Educaçấo- III CONEDU.

${ }^{2}$ Silva corroborando com as ideias de Pessotti destaca que este fato se dá porque "o conteúdo da doutrina cristá que era toda voltada para a caridade, ou seja, para o amor ao próximo, para o perdáo das ofensas, para a valorizaçáo e compreensão do significado da pobreza, da simplicidade de vida e da humildade, conteúdo esse pregado por Jesus Cristo e divulgado com nuances cada vez mais convincentes, conquistou a grande horda dos desfavorecidos em primeiro lugar".

${ }^{3} \mathrm{O}$ estudo do autor focou-se no corpo de profissionais que trabalhava com pessoas com autismo, tendo em vista a relaçáo de alteridade entre ambos. Ele observou em seus resultados uma dificuldade dos e das profissionais, que atendiam as pessoas com autismo, em reconhecê-las como sujeitos, o que acarretava diretamente a aprendizagem das pessoas com autismo. 
Thyeles Moratti Precilio Borcarte Strelhow

\section{Correspondência}

Thyeles Moratti Precilio Borcarte Strelhow - Faculdades EST. Rua Amadeo Rossi, 467 - Morro do Espelho, São Leopoldo. CEP: 93020-190. São Leopoldo, Rio Grande do Sul, Brasil.

E-mail: thyelesbs@yahoo.com.br

Correspondência em 1 de dezembro de 2016

Final em 2 de abril de 2018 